Gavazzo, Natalia: "La diasporización de los hijos: identificaciones y relaciones intergeneracionales en familias bolivianas y paraguayas en Buenos Aires"; en $R E A, \mathrm{~N}^{\circ}$ XXIII, 2017; Escuela de Antropología - FHUMYAR - UNR; pp. 81-107.

\title{
La diasporización de los hijos: identificaciones y relaciones inter-generacionales en familias bolivianas y paraguayas en Buenos Aires
}

\author{
Natalia Gavazzo \\ Instituto de Altos Estudios Sociales \\ Universidad Nacional de San Martín \\ Universidad de Buenos Aires \\ CONICET \\ navegazzo@yahoo.com
}

\section{Resumen}

En este artículo se examinarán diversas identificaciones que se construyen en la generación de jóvenes argentinos hijos de inmigrantes bolivianos y paraguayos en Buenos Aires. Se parte de que las relaciones inter-generacionales en las familias migrantes son centrales en el contexto de comunidades parentales transnacionales que se relacionan mediante representaciones y prácticas compartidas. Se atenderá, entonces, a la construcción de identidades diaspóricas entre los descendientes como grupo específico a partir de las relaciones que construyen con sus padres, abuelos y hermanos, y también con sus familias extendidas a ambos lados de las fronteras nacionales.

\section{Palabras clave}

Diáspora - Segunda generación - Familias migrantes - Identificaciones - Relaciones intergeneracionales

\section{The diasporization of the descendants: identifications and inter- generational relationships among Bolivian and Paraguayn families in Buenos Aires}

\section{Abstract}

This article examines varied identifications among the young second-generation 
GavAzzo, Natalia - "La diasporización de los hijos..."

Bolivian and Paraguayan migrants in Buenos Aires. On the basis of the centrality of intergenerational relationships in migrant families in the context of transnational parental communities that relate each other through shared representations and practices. It will focus on Diaspora identity construction among descendants as a specific group since the relationships they build with their parents, grandparents and siblings, and also with their extended families at both sides of the national borders.

\section{Keywords}

Diaspora - Second-generation - Migrant families - Identifications - Inter-generational relationships

\section{Introducción: diásporas a través de las generaciones}

Para comprender la inserción de los migrantes en los lugares de destino, una alternativa a términos como "comunidad" y "colectividad" (cuestionados por su tendencia homogeneizante) es el de diáspora, que en su acepción originaba denominaba una red de personas viviendo en dispersión involuntaria fuera de sus lugares de origen y que, por decisión propia o ajena, resisten a asimilarse completamente a los lugares de residencia, constituyendo aquello que Clifford (2002) denominó "culturas viajeras". Fue caracterizada, además, por los sentimientos de lealtad hacia el origen, el anhelo de retorno, y la persistencia de identificaciones colectivas a través de varias generaciones (Merenson, 2015:212). En los últimos años, se analizan también los procesos de articulación de las relaciones simbólico-materiales entre lugares de origen y de residencia (Mera, 2010)를 vinculándose esta noción a la de "comunidades transnacionales" (las cuales no necesariamente constituyen una diáspora).

Con todo, no todo desplazamiento de personas desde un mismo lugar de origen implica un fenómeno diaspórico, pues ni todas las socie-

1. Mera afirma que el término "diáspora" permite analizar tanto la vinculación con el lugar de origen y la integración o no a la sociedad global, como los mecanismos de adhesión étnica generados en las comunidades migrantes. Difiriendo de la rigidez otorgada al término en su concepción clásica, lo vinculamos, en la actualidad, a la hibridez, fluidez y transformación. 
dades, naciones o culturas generan identidades diaspóricas (Grimson, 2011:144). Cuestionando nociones esencializadoras de cultura, identidad y origen étnico, y acentuando la agencia, algunos estudios comenzaron a explorar los "procesos de diasporización" a partir de los cuales se (re)produce un grupo que se autopercibe y es percibido como una “comunidad" (Olsson, 2009 en Merenson, 2015:212). Así se busca escapar al esencialismo del que fueron objeto "comunidad" y "colectividad", afirmando que las causas de dispersión son más amplias, que no remiten solo a su carácter forzado, que el lugar elegido para residir es frecuentemente resultado de procesos de redes o cadenas migratorias, que conforman un fuerte sentido de comunidad que recae sobre la memoria y el vínculo con el territorio de origen y que realizan un trabajo de transmisión intergeneracional de la identidad.

Este artículo sugiere que una de estas maneras de "diasporizarse" es a través de las redes familiares y, especialmente, del vínculo entre padres, hijos, abuelos y hermanos. Por ello, abordaremos la centralidad de las familias en la construcción de una memoria -individual y diaspórica- en el contexto de comunidades parentales transnacionales. ¿Cómo se identifican los hijos? ¿Se sienten parte del lugar en que nacieron sus padres o en el que ellos nacieron y donde viven en la actualidad? ¿Constituyen una generación distinguible de la de sus padres y abuelos? ¿Qué implicancias tienen esas identificaciones en las relaciones inter-generacionales?

Las identificaciones de las generaciones de hijos de inmigrantes a lo largo y ancho del mundo configuran un tema de interés para los propios migrantes, para los Estados, y para los investigadores sociales. En los estudios que examinan estas cuestiones los hijos e hijas suelen aparecer como un grupo -como una "generación"- visible pero frecuentemente considerado parte de un conjunto mayor definido y "marcado" como "inmigrante".

Sobre lo anterior, cabe explicitar que el concepto de generación 
GavAzzo, Natalia - "La diasporización de los hijos..."

tiene múltiples sentidos ${ }^{2}$ y que aquí lo definimos desde las relaciones de parentesco: nos referiremos a una generación como la de "nuestros abuelos", "nuestros padres", "nuestra" o de "nuestros hijos" o "nietos" (Kropff, 2008). ${ }^{3}$ Preconizamos estudiar la genealogía, la filiación, la maternidad/paternidad y las pautas matrimoniales "debido a que los inmigrantes y sus descendientes viven una gran parte de sus vidas y frecuentemente desarrollan sus relaciones más importantes en las familias, (de modo que) lo que suceda en la arena familiar tiene enorme significación" (Foner, 2009:17). Así, un análisis de las dinámicas familiares es central para comprender las experiencias de los padres, las de los hijos y la implicancia de las relaciones intergeneracionales en la construcción de identidades diaspóricas en un grupo específico.

Por otro lado, cabe subrayar que se incluye a los hijos dentro del número de migrantes de cierto origen residentes en una localidad, o de las comunidades diaspóricas internacionales provenientes de un mismo sitio, tanto para resaltar su importancia "somos muchos", como para denunciar su ilegitimidad "son invasores”. Pero ¿Hasta qué punto pueden ser estos nativos considerados parte de las comunidades de inmigrantes? ¿Pueden los hijos de inmigrantes nacidos en destino ser considerados parte de la diáspora?

Atendiendo a estas cuestiones desde un caso particular -y corrobo-

2. Según su etimología, generación es la creación de vida (la fecundación y procreación); y las generaciones, las distintas modalidades en que se cumple esta función (Ghiardo, 2004:14). Esta dimensión biológica es central: sin reproducción no hay sucesión de descendientes en línea recta, sentido que el segundo significado atribuido a la palabra (remitiendo a la cadena hijo-padre-abuelo). Un tercer significa se observa al examinar la posición de ciertos sujetos en la estructura de edades de una sociedad: una generación definida como grupo y/o grado de edad. Un cuarto sentido deviene de un enfoque socio-político que -como veremos-influye en las categorías de identificación utilizables para "clasificar" a estos hijos, especialmente "los que participan".

3. Con este componente relacional "la generación deja de ser solamente una acción (generar) y una función (reproducción)", comprendiendo, además, aquello que ellas producen: "una cadena de filiaciones" y "las relaciones de parentesco" (Ghiardo, 2004:14). 
rando la construcción de una mirada antropológica de las migraciones a través de las generaciones-, se examinarán diversas identificaciones construidas entre jóvenes argentinos hijos de inmigrantes bolivianos y paraguayos en el Área Metropolitana de Buenos Aires (AMBA) ${ }^{4}$, en relación al origen de sus padres. Estas nacionalidades representan-según el Censo 2010 - cerca del 50\% de la población extranjera que reside en el país y en esta ciudad. Por lo mismo, se analizó previamente, y en perspectiva comparada (Gavazzo, 2012; 2013), el rol de familias migrantes de ambos orígenes en la construcción de sentidos de comunidad, y las relaciones/conflictos intergeneracionales referentes a la identificación y diferenciación.

Aquí, examinaremos la constitución del sujeto hijo ${ }^{5}$ en estas familias, enfocándonos en las relaciones intergeneracionales: aquellas que los descendientes de bolivianos y paraguayos construyen con quienes conforman "otras generaciones" de parientes. Enfatizaremos las relaciones entre padres e hijos, aunque observando los vínculos que los hijos establecen con otros parientes - de la misma generación (hermanos y/o primos) o de otras (como abuelos y parientes que residen en el AMBA y en el lugar de origen de los padres). Con base en materiales provenientes de un trabajo de campo de largo aliento 6 , se mostrará cómo esto "im-

4. Esta área comprende a la Ciudad Autónoma de Buenos Aires (CABA) y a veinticuatro municipios lindantes de la Provincia de Buenos Aires. Es conocida como "Gran Buenos Aires" (GBA).

5. Nos referimos, principalmente, a las representaciones y significaciones del "ser hijo". En los testimonios recopilados, la denominación hijo aparece como una "categoría nativa". Pero se propone constituirla también, desde una crítica al concepto de segunda generación (Gavazzo, 2012; 2013), como "categoría analítica".

6. La investigación en la que se basa este artículo se inició en 1999 y adoptó un enfoque etnográfico que - especialmente en el período que va de 2007 a 2012 cuando realicé el Doctorado en Antropología - me orientó en el trabajo de campo y me permitió construir un corpus de datos compuesto por una variedad de referencias: 1) observaciones con participación: principalmente de las actividades comunitarias en las que participan los hijos de bolivianos y paraguayos, pero también en las agencias estatales y en las organizaciones de la sociedad civil con las que interactúan, ya sea en los barrios, en los hogares, como en otros espacios 
GavAzzo, Natalia - "La diasporización de los hijos..."

pacta" en los modos de identificación de aquellos hijos de bolivianos y paraguayos que, nativos argentinos, tienen al menos un padre nacido en Bolivia y/o Paraguay.

Las preguntas e hipótesis que guiaron la investigación están detalladamente expresadas en mi tesis doctoral (Gavazzo, 2012), pero baste decir que todas ellas se enfocan en personas consideradas "jóvenes": aquellas atravesando desde la adolescencia hasta la primera fase de la adultez, a los 40 años. Si bien se trata de un conjunto heterogéneo de sujetos y subjetividades, no obstante, como veremos a continuación, comparten algunas características vinculadas a experiencias comunes familiares, comunitarias y sociales que marcan sus formas de auto-identificarse y de presentarse.

\section{La familia migrante: relaciones y conflictos intergeneracionales}

En los numerosos estudios sobre relaciones familiares migrantes realizados en los últimos quince años -especialmente en Estados Unidos y Europa- suele afirmarse que, para aquellos que crecen en familias migrantes, es difícil "reconciliar la orientación en el lenguaje y la cultura de los padres extranjeros con las demandas de asimilación de la sociedad receptora" (Portes, 1997:248). Niños migrantes o hijos de inmigrantes

significativos para los sujetos; 2) entrevistas en profundidad, semi-estructuradas: unas 60 entrevistas en total: 40 a hijos ( 20 de bolivianos y 20 de paraguayos, con un equilibrio en términos de género, edad, y origen rural-urbano, entre otros factores, especialmente con aquellos que participan de organizaciones), 10 a padres (de algunos de estos hijos, 5 de cada comunidad) y 10 a "otros" (categoría más indefinida que contempla amigos, vecinos, parejas, cónyuges, compañeros de trabajo, de escuela, entre otros, y también funcionarios del estado y empleados públicos que interactúen con esos hijos, incluyendo médicos, enfermeros, docentes y asistentes sociales, entre otros); 3) historias de vida: de los miembros algunas familias y de algunas familias; 4) material de archivo: desde publicaciones, volantes, documentos de las organizaciones, recuerdos y fotos, hasta sitios web, textos de programas y políticas públicas e incluso periódicos y revistas publicadas por medios masivos de comunicación pero también comunitarios. 
parecen encontrarse con un dilema personal: si "se mantienen" parecidos a sus padres -en nuestros casos "bolivianos" o "paraguayos"-, se enfrentarán al ostracismo social y continuarán los ataques en la escuela. Pero si "se convierten" en locales - "argentinos" en nuestro caso-, deberán "alejarse de los sueños de sus padres de progresar sin perder la solidaridad étnica y la preservación de valores tradicionales" (Portes, 1997:244). Esta tensión podría culminar en el rechazo de la cultura parental o en un repliegue hacia adentro de la comunidad migratoria, para no confrontar con la sociedad "exterior". Sin negar la validez de estos debates, identificamos en las relaciones familiares de los hijos de bolivianos y paraguayos en el AMBA, más opciones que aquellas señaladas por estos estudios. Para abordar estas particularidades, conviene sintetizar dos vertientes teóricas predominantes sobre los hijos de migrantes en el denominado Norte Global.

La primera, es la teoría de la asimilación segmentada, que se enfoca en los "patrones de adaptación" de los migrantes contemporáneos y sus descendientes. Estos patrones van de la "aculturación" (con inclusión en la clase media) hasta la "movilidad social descendente" (con incorporación a las clases bajas) y el "avance económico a través de la preservación de los trazos étnicos únicos" (que puede implicar, asimismo, incorporación a la clase media) (Portes y Zhou, 1992:54). La segunda, es el transnacionalismo: un conjunto de estudios que enfatizan los tipos de conexión que los migrantes contemporáneos mantienen con sus países de origen. ${ }^{7}$ Muestran que un creciente número de inmigrantes sostienen lazos económicos, políticos y religiosos con sus países de origen mientras trabajan, votan y rezan en los países donde viven (Levitt y Waters, 2002:2). Así, se genera un interés por las prácticas transnacionales de los hijos de los inmigrantes. Ambas perspectivas serán útiles para dar cuenta -en el último apartado- de las formas heterogéneas con que los hijos de

7. Para el caso boliviano en Buenos Aires: Benencia (2006) y Caggiano (2005). Para el caso paraguayo: Halpern (2009). 
GavAzzo, Natalia - "La diasporización de los hijos..."

bolivianos y paraguayos se identifican como parte de una generación y cómo sus visiones de mundo se asemejan y/o difieren de la de sus padres.

No obstante, las relaciones de parentesco y familiares deben estudiarse en el contexto de la sociedad mayor, atendiendo a las categorías de identidad propias de los hijos de bolivianos y paraguayos y a las socialmente atribuidas a ellos. La familia inmigrante no puede ser entendida aisladamente de su contexto inmediato. Un análisis de las relaciones intergeneracionales dentro de dichas familias "debe inevitablemente tomar en consideración las instituciones y prácticas sociales, económicas, políticas y culturales del contexto mayor" (Foner, 2009:12). Observándose la historia argentina y el lugar del AMBA en la atracción de inmigración de países de la región, especialmente Bolivia y Paraguay, comprenderemos que diferentes generaciones comparten cierta "imagen pública", o sea, representaciones sobre estos inmigrantes vinculadas a formas de percibir, conceptualizar y significar los procesos sociales desde modelos ideológicos construidos históricamente y que generan, simultáneamente, prácticas concretas (Sinisi, 1999:45). Cuando las representaciones del propio grupo son valorizadas socialmente como positivas, los sujetos de referencia serán "reconocidos" y "legítimos" y obtendrán prácticas de respeto y aceptación. Cuando son imaginados mediante estereotipos negativos, el efecto derivado es la estigmatización.

Bolivianos, paraguayos y otros grupos de la región comparten el estigma de "inmigrantes no deseados". En oposición a los europeos, son concebidos en ocasiones como un todo, como un grupo único ${ }^{8}$. Esta operación de unificación y homogeneización define a los inmigrantes intrarregionales como un símbolo del "atraso", "primitivismo" y "subdesarrollo" del que Argentina "emergió" gracias a los inmigrantes transatlánticos que aportaron la cuota de "civilización", "modernización" y "progreso" a la nación desde el siglo XIX. Ciertamente, -aunque el relato nacional les asignó este rol fundamental-, los europeos fueron tam-

8. Ver Ratier (1972); Oteiza Novick Aruj. (1997); Margulis y Urresti (1999); Caggiano (2005). 
bién discriminados. Pero en nuestros estudios de caso, los inmigrantes y sus hijos comparten un estigma desplazado, invisibilizado en el discurso sobre "crisol" que compone la nación argentina.

Así, mecanismos de la legitimación de su desigualdad -como hijos de inmigrantes no deseados- operan a través de la reproducción de los estereotipos negativos "heredados" de los padres. Se produce una "marcación étnica" de estos descendientes, una "alterización”: ellos son percibidos como "diferentes" de los nativos argentinos. Este proceso se ve fortalecido cuando la comunidad en la que nacen estos hijos se caracteriza por la solidaridad comunitaria (Gavazzo, 2012) y por las redes sociales que fomentan la "preservación" de la identidad nacional para el éxito individual (Portes, 1997). Los ideales promovidos por "primera generación" con el fin de mantener ciertas pautas culturales "de origen" -sobre todo en este contexto de "extranjerización" de los hijos nacidos en Buenos Aires- puede entrar en contradicción con la experiencia cotidiana de los niños y adolescentes, por ejemplo en las escuelas ${ }^{9}$. ¿Cómo impacta la alterización de los hijos y su inclusión dentro de la comunidad migrante transnacional o diaspórica en las relaciones intergeneracionales al interior de las familias migrantes bolivianas y paraguayas en Buenos Aires?

\section{De padres a hijos: transmisión y asimilación}

Algunos estudios realizados sobre descendientes afirman que tanto padres como hijos comparten una cultura común que se "transmite" de una generación a la otra. Esta idea de la "maleta cultural" ha sido fuertemente criticada (Grimson y Godoy-Anativia, 2003), pero es posible afirmar que, en su interacción cotidiana, los hijos y sus padres comparten relatos, valores y formas de ver el mundo vinculadas a lugares de origen.

9. Interesantes trabajos analizan la inserción escolar de los niños migrantes e hijos de migrantes en Buenos Aires, especialmente de bolivianos (Sinisi, 1999; Beherán, 2007; Novaro y otros, 2008), resultando realmente útiles para pensar en las identificaciones de los hijos. 
GavAzzo, Natalia - "La diasporización de los hijos..."

Además, padres e hijos son imaginados y clasificados (autoimaginados y autoclasificados, incluso) frecuentemente como parte de una misma "comunidad".

Actualmente, se tiende a asumir una continuidad indiscutida entre padres e hijos, sin registrar el cambio cultural y la nueva situación de interacción. Estos modelos ideológicos pueden vincularse con la nacionalidad (argentina, boliviana y paraguaya) aunque la exceden por mucho, llegando a comprender otros ejes identitarios como la región, la etnicidad, el género y la clase social ${ }^{10}$.

Observamos, en los testimonios recopilados durante el trabajo etnográfico, que existe frecuentemente una identificación de los hijos con los padres en relación a ciertas prácticas, ideas y valores de la vida cotidiana vinculada a Bolivia y Paraguay. Walter, por ejemplo, nació y creció cerca del barrio Atalaya en el Partido de La Matanza en el Gran Buenos Aires (GBA). Tiene 33 años y es hijo de ambos padres bolivianos. Recuerda que su madre Yolanda, que trabajó de empleada doméstica toda su vida, celebraba la ceremonia doméstica del $1^{\circ}$ de noviembre, el Día de los Muertos:

Mi mamá hacía todos los santos, se lo decía mi abuela, su mamá. Ahora ya, mi mamá es evangelista; ya no lleva esas costumbres; ella no escoba la casa, pero antes sí lo hacía; escobaba la casa. Todos los santos era dejar una ofrenda para los difuntos, orar. De eso sí me acuerdo.

Por su parte Mercedes tiene 29 años, nacida en el sur de la Ciudad Autónoma de Buenos Aires (CABA) e hija de padres bolivianos, es actualmente vecina de Pompeya y reconoce que su experiencia no es la misma que la de muchos de estos amigos porque:

Lo que yo recuerdo de esa época, de mi infancia, era que íbamos cada año a Luján, yo lo que tenía la imagen era que íbamos por un reen-

10. Como no existe representación sin práctica social, esos patrones culturales funcionan como modelos de la identificación y generan simultáneamente prácticas concretas: hablamos tanto de ideas como de (inter)acciones (Sinisi, 1999:45). 
cuentro familiar, no sabía que íbamos a ver a una virgen, que íbamos a festejar el día de la Independencia, el día patriótico de Bolivia, el 6 de agosto (...) nosotros, mi generación de chicos, de hijos de bolivianos de mi familia no pensábamos que era eso (...) Al criarme más con mi abuela, que es argentina, tampoco se hablaba de las danzas, ni de la cultura.

$\mathrm{N}$ : ¿Tu mamá no te contaba?

M: No, porque era otra época, y como que ella también...no se había olvidado pero no teníamos referencia, más que todo (...) Sabía que mi mamá era boliviana, sabía que había nacido allá, que se había venido, pero la danza en sí no la conocía (...)

La construcción de una memoria del país de origen de los padres se da en la interacción cotidiana con los hijos, quienes van seleccionando algunos de aquellos elementos para sí mismos. Esto puede unirlos en "relaciones comunitarias" que funcionan como red de contención y ayuda en interacción cotidiana en el ámbito familiar (o como un espacio de sentido compartido). Así, es frecuente un acercamiento de los hijos a las culturas de los padres mediante formas de imaginar la nación de origen y a prácticas vinculadas a ella.

Asimismo, esta construcción se da de modos diferentes, de acuerdo a factores que van desde la decisión de emigrar, el contexto familiar previo y la inserción posterior en el lugar de destino. Varían también de acuerdo a las herramientas de transmisión de que dispongan los padres, lo que se correlaciona a la región o ciudad de su procedencia, a las creencias de cada uno y su clase social. En los relatos, algunos aspectos de la supuesta "herencia cultural" resultan "extraños" para descendientes cuando son niños y adolescentes, dificultándoles identificarse con ella como una totalidad. Esto se verifica en aquellos casos en que los hijos no tienen contacto con otras familias del mismo origen y cuando están expuestos a contextos de discriminación y segregación. Tomemos el caso de Nancy, que tiene 22 años, y es hija de ambos padres bolivianos, quien cuenta:

Mi vieja hablaba muy mal el castellano; lo aprendió a hablar mejor 
GavAzzo, Natalia - "La diasporización de los hijos..."

cuando fue a trabajar en Potosí, de empleada doméstica; cuando salió de su pago, había ido a trabajar a la zafra, todo eso, en el Norte de Argentina y después, hizo un tiempo largo de empleada doméstica; mi vieja salió a los 15 años de su pago; estuvo 5 años de laburo fuera de su casa. Y en ese tiempo que estuvo trabajando en Potosí, ahí empezó a hablar más; dice que tenía una patrona que era buena, que le enseñaba a hablar un poco más el castellano, así que... O sea, algo sabía, pero no lo manejaba bien; eso es lo que me decía mi vieja.

Luego comenta que su padre "no quería que laburara" sino que "lo que quiere es que yo termine de estudiar", razón por la que asistió a una escuela "lejos de casa" (en su caso, "en el centro") en donde no había otros hijos de migrantes como ella. Desde su percepción, esto marcó su carácter y su modo de ser en toda la época escolar hasta más adulta:

Cuando era más chica; yo, cuando era más chica, era muy tonta, muy tonta. (...) Me pisaban en todos lados, te juro. En el negocio sí; me ha pasado un montón de veces; por ahí no me sabía los precios; me ponía nerviosa y los comentarios, así, aunque sea en voz baja, me dolían, me llegaban. Y yo no les decía nada. O, por ahí, en la escuela, que ahí fue más fuerte; me insultaban y me hacía la que no escuchaba. Y no me defendía; no sé, era tan... Era como que sentía que reproducía eso que le pasaba a mi viejo, pero conmigo.

El extrañamiento hacia las costumbres de los padres puede incluso hacer que los hijos "altericen" a la propia familia y se sientan alienados, percibiendo a sus padres como "otros" radicalmente diferentes (llegando a discriminarlos por resistirse a la semejanza). En todos los casos, la percepción de los hijos acerca de "alteridad" de los padres también se va construyendo y cambiando a lo largo de la vida. Aun cuando no hayan crecido en un barrio boliviano o paraguayo, la casa compartida con la familia es para ellos un ámbito vinculado a esas nacionalidades (ya sea en la representación "amada" u "odiada").

A pesar de que la discriminación sucede, en ocasiones la "alteridad" -que se apoya por la difusión de los estereotipos sobre los migrantes- es bastante más ambigua. A medida que los hijos incrementan sus conoci- 
mientos del país de origen, aquello que les parecía "extraño" se vuelve más y más habitual. Tomemos el caso de Laura que tiene 32 años y que, aunque nació en San Carlos de Bariloche, vivió, estudió y trabajó en Buenos Aires casi toda su vida. Ambos padres son de Asunción y vienen de familias de clase media, lo que les permitió estudiar en la universidad.

Mi mamá se identifica como paraguaya básicamente (...) tiene esas cosas de pertenencia de infancia, que son muy poéticas y muy lindas. Entonces yo tenía la información de que ella era paraguaya; incluso había ido a Paraguay y todo, pero jamás fue tratada como paraguaya. Hasta que se tuvo que jubilar. Y le dijeron: "pero usted no es argentina; es naturalizada". "Sí". Tenía toda su trayectoria, sus documentos, su escuela; todo lo hizo en Argentina, pero "en qué fecha entró al país". Y ella no sabe en qué fecha entró al país. (...) "Mirá, estoy segura de que cuando empecé la primaria, estaba acá, porque fui a la primaria tal". "No, pero necesito la fecha". No sé cómo mierda terminó solucionándolo, qué papel oficial encontró ella de su primera infancia y la cosa es que ahora le figura como que entró a los 10 años a la Argentina o algo así, pero no le podían iniciar el trámite jubilatorio porque era paraguaya de origen. Ahí volvió y dijo "¿Vos sabés que tenés razón? Sos primera generación nacida en Argentina". Porque cuando yo le dije "Mamá, yo soy primera generación nacida en Argentina" "No; pero..." "Sí, mamá”. "Ah, tenés razón”. Nunca vivió ella, nunca se definió a sí misma como migrante.

Distinto es el caso de su padre:

Mi viejo se fue de Paraguay y no quiso saber nada más de Paraguay y cortó absolutamente todo el lazo que pudo. Es más, cuando fui yo cuando era chica, a Paraguay, fui porque mi mamá tomó la decisión de que yo tenía que conocer a mi familia paraguaya. Mi viejo no se banca la sociedad paraguaya; nunca te hace un recuerdo de la cotidianeidad del Paraguay como algo copado. (...) Lo único que recuerdo la música; recuerdo discos de vinilo que tenía mi papá de música paraguaya y vos fijate: él tocaba. De hecho, hoy en día, él toca el acordeón a piano; toca polcas. Tengo eso y, después, las puteadas de mi viejo cuando entraban las vacas en el patio y las mulas del Ejército 
GavAzzo, Natalia - "La diasporización de los hijos..."

y las chivas de los vecinos y había que sacarlas, mi viejo pelaba el machete y entraba, insulto en guaraní, a sacar las vacas a la mierda.

Por ello, las identificaciones de los hijos pueden oscilar entre la proximidad y la distancia en cuanto a cómo se vinculen con el país de origen de sus ascendientes. Esto denotará sentimientos de pertenencia que pueden cambiar en el mismo relato (y en distintos contextos o frente a distintas audiencias). Según la teoría de la asimilación, si los padres rompen lazos con el país de origen y se identifican gradualmente como locales (como "porteños" o "argentinos"), los hijos desconocerán aspectos de la cultura de sus padres, especialmente las visiones de éstos sobre aquella. Sin embargo, mismo en aquellos casos en que los hijos no hayan participado de prácticas domésticas vinculadas al país de origen de sus padres (desde ceremonias hasta alimentación típica), en casos donde no hubiera una "transmisión activa" de saberes, lejos de sentirse "aculturados" estos hijos relatan que Bolivia y/o Paraguay forman parte de su vida desde niños. Pero esta "proximidad" a las culturas bolivianas y/o paraguayas no significa que no se reconozca las diferencias, como muestra el relato de Daiana. Ella nació en el barrio Caballito en la CABA, tiene 20 años y es hija de ambos padres paraguayos, con quienes reside en ese barrio hasta la actualidad. Al respecto de su madre, Francisca, de 45 años, empleada doméstica nacida en Asunción, ella opina:

O sea, mi mamá, ponele, que tiene su corazón en Paraguay pero también tiene acá, porque acá vino sola, porque a mi papá lo conoció acá. Vino sola; se rompió el lomo. Después lo conoció a mi papá; me tuvo a mí; se casaron. Después tuvo a mi hermano. Entonces es como que tiene todo acá, su vida. Y allá también tenía su vida; tiene parte de su vida. Y acá también; es un sentimiento encontrado.

Los viajes para visitar la familia en origen influyen en esto enormemente:

Voy [a Paraguay] porque están sus familiares [los de sus padres] y [ellos] extrañan; es como que... Es donde nacieron. Y antes, bueno, cuando estaban sus padres vivos, mi mamá, ponele, le tenía mucho 
afecto ¿sabés? Extrañaba eso. Ahora, como que va a ver a los hermanos, pero no es como antes, que iba a ver a sus viejos y estaba feliz; ahora es como que, si pasan 2 años, está todo bien. Y, como en toda familia, algunas cosas se parecen y otras, no. (...) en realidad, nadie va a ir a vivir allá. Mi papá solo quiere ir, porque mi mamá ya se adaptó acá, estamos mucho mejor acá. Allá es como lavar a mano, todo y acá, todo es (...) más comodidades. Es más seguro.

En un contexto de identificaciones cambiantes, existen numerosos factores que pueden marcar diferencias casi infranqueables entre padres e hijos (constituyendo también barreras en las relaciones sociales más amplias con el "afuera" de la familia). Entre ellos se destaca el idioma. La "marca" de la lengua (no solo del quechua, aymara y guaraní11, sino de las formas de hablar, la tonada y el léxico) constituye un punto compartido entre algunos hijos de bolivianos y paraguayos que se sienten diferentes a sus padres. Por veces, los hijos se convierten en "intérpretes de los padres" en diversos contextos (como visitas a oficinas públicas, hospitales, entre otros).

Esto nos lleva a reflexionar sobre tres elementos de la identidad: los atributos objetivos, los vínculos y los sentidos de pertenencia (Brubaker y Cooper, 2002). Los "atributos" se refieren a cualidades objetivas y a las clasificaciones sociales que le son imputadas, ya que el hecho de que algunas personas sean socialmente consideradas miembros de un grupo no implica que ellas detengan un sentimiento de pertenencia. No todo contacto o relación social -en este caso, de parentesco-implica identificación: el que las personas se comuniquen a diario no necesariamente lleva a que se identifiquen entre sí. En otros casos, personas que no tienen contacto pueden sentirse parte de una misma comunidad. De ahí que -y he aquí un hecho central de este artículo-, las articulaciones entre atributos, vínculos y pertenencias no sean auto-evidentes.

11. Quechua y aymara son propios de los pueblos originarios de Bolivia central (donde reside la mayor parte de la población indígena del país). El guaraní es la lengua de los pueblos del Paraguay. Actualmente son consideradas lenguas oficiales de ambos países, aunque persista una marca elitista discriminatoria hacia ellos. 
GAVAzzo, Natalia - "La diasporización de los hijos..."

Más allá de las diferencias, las narraciones sobre la experiencia migratoria contadas por los hijos recuperan relatos escuchados de sus familiares (especialmente de sus padres), al que evocan cuando preguntados sobre Bolivia y Paraguay. En ese sentido, tenemos el testimonio de Fernando, que vive en Parque Patricios en la CABA, aunque por muchos años vivió en Valentín Alsina, en el Partido de Lanús del GBA. Tiene 50 años y es hijo de ambos padres paraguayos. Está casado con una mujer paraguaya con quien tiene 2 hijos argentinos. Según comenta:

Los paraguayos, que salimos del Paraguay no somos paraguayos, nos discriminan, vamos a Paraguay y no somos paraguayos, somos porteguayos, somos porteños, somos curepa...me duele pero entiendo, yo sé el origen, la dictadura, fue una forma de decir "no ellos no se van por cuestiones políticas...se van porque son malos paraguayos, eso fue durante toda una vida, entonces el paraguayo que se fue, es un mal paraguayo, el paraguayo que habla mal de la realidad paraguaya, está hablando mal del Paraguay, es un apátrida.

Rituales domésticos, consumos culturales, viajes al país de origen y visitas de parientes, constituyen los espacios en que esos relatos circulan dentro de las familias, vinculando padres e hijos a partir del compartir un conocimiento que puede servir (o no) para la identificación mutua. Las fiestas familiares que posibilitan también la circulación de relatos e información sobre Bolivia y Paraguay. Y no solo es cuestión de que los padres quieran enseñarles a los hijos. En ocasiones, es la curiosidad de los propios hijos la que fuerza a los padres a recordar (y compartir) prácticas y creencias de las tramas culturales que incorporaron en origen.

Los estudios realizados desde la teoría de la asimilación otorgan centralidad a la situación socioeconómica de los padres y las familias, subrayando su influencia en la estructuración de las relaciones entre padres e hijos, en la circulación de relatos, en la construcción de una memoria y en las trayectorias educativas y laborales. Sin dudas, la clase social constituye un eje de identificación que se puede articular con la nacionalidad de los padres, especialmente en procesos de movilidad social ascendente o descendente (que pueden generar conflictos y rupturas en 
las relaciones). Aunque no es determinante, el contar con un capital económico que permita acceder a información y consumos, a las actividades vinculadas a las "culturas nacionales" de Bolivia y Paraguay antes mencionadas, produce diferencias en las identificaciones de los hijos. Existe, finalmente, otro factor importante en las relaciones intergeneracionales: la antigüedad en el ingreso de los padres al país. La permanencia en Argentina facilita a los migrantes progresar económicamente y generar relatos "exitosos" que acercan a los hijos a las historias de sus padres.

Asimismo, estas prácticas comunes pueden constituir un foco de conflictos en las relaciones intergeneracionales. Numerosos estudios parecen justamente enfocarse en estas tensiones entre padres e hijos acerca de la disciplina parental, las elecciones matrimoniales, las expectativas educacionales y ocupacionales de los padres hacia ellos (Portes, 1997; Feixa, 1996; Pedone, 2010).

En nuestro estudio de caso, estos conflictos se acrecientan por la estigmatización de los hijos en tanto descendientes de inmigrantes "no deseados". El dilema mencionado por Portes sobre la "asimilación" de los hijos a la cultura local representa un desafío considerable no solo para ellos (que deben combinar la educación en la casa familiar con la que reciben en las escuelas argentinas), sino también para quienes emprenden un análisis de las diversas estrategias de "integración" que ellos desarrollan. Especialmente cuando estos análisis restringen al "plano cultural" la comprensión de la "absorción" de los grupos de inmigrantes en la sociedad receptora (Portes, 1997).

Los estudios clásicos asumen que la "asimilación" lleva progresivamente a la "aculturación": a una inserción social con "pérdida de identidad", con la discontinuidad de ciertas prácticas y creencias. Eso, a su vez, promovería la movilidad socioeconómica de los hijos. Así, para "integrarse", los inmigrantes deberían promover que sus hijos no aprendan sobre su "cultura de origen" y que se "sumerjan" en la cultura local para poder "progresar" y "ser exitosos".

En cambio, otros debates asumen que la asimilación no lleva necesariamente al progreso económico y la aceptación social, derivando, pre- 
Gavazzo, Natalia - "La diasporización de los hijos..."

cisamente, en resultados opuestos (Portes, 1997; Portes y Zhou, 1992). Al no poseer ni disponer del capital social y cultural de la comunidad de pertenencia de sus padres, los hijos ven truncada su inserción social (entendida no únicamente como su incorporación al mercado laboral sino a partir de la valoración positiva de su identidad cultural) (Portes, 1997).

Los datos recopilados durante la investigación permiten caracterizar un conjunto heterogéneo de identificaciones. En ellas, las relaciones intergeneracionales no siempre siguen a estas afirmaciones teóricas de carácter general. De las opciones identitarias observadas, ninguna conlleva necesariamente conflictos entre padres e hijos. Influyen en esta conflictividad otros factores: desde la personalidad, hasta el contexto social que rodea al hijo y las circunstancias históricas que enmarcan su proceso de identificación. Las relaciones intergeneracionales dependen de la combinación de todos estos factores en cada caso particular.

Desde la perspectiva de los padres, la cuestión tiene sus propias aristas. Algunos de ellos, que han sido educados y son comprometidos con los problemas de su comunidad, no logran "preparar" a sus hijos para abrirse paso en un contexto adverso. Incluso cuando los padres son activos (al compartir recuerdos y construir una memoria común), el impacto en los hijos no resulta similar, por lo menos, desde la perspectiva de los primeros. Los hijos pueden aceptar o no esa "herencia", pero en todos los casos, y de forma diversa, la contradicción implicada en esta "doble identificación" de los hijos (ser argentinos y bolivianos o paraguayos) parece repercutir en las relaciones intergeneracionales.

A pesar de que el "estigma heredado" puede alejar a los hijos de sus padres, las relaciones intergeneracionales y especialmente las que vinculan padres con hijos, no se componen únicamente de tensiones y conflictos: también existen lazos que los unen y acercan de modos que resuelven, acomodan y comprometen. Se crean compromisos mutuos como una manera de llevarse mejor. ${ }^{12}$ Un número importante de descen- 
dientes no son rebeldes ni rechazan o abandonan enteramente las formas de sus padres. Más allá de lo que los hijos (especialmente los jóvenes) piensen sobre los estándares de sus padres, se observa una tendencia general hacia la conciliación entre los comportamientos para evitar choques, tomando en cuenta, al menos, parte de las expectativas que se proyectan sobre ellos ${ }^{13}$. No se trata de "celebrar o lamentar incondicionalmente" estas nuevas formas de pertenencia a través de las fronteras, sino de explorarlas para comprender sus lógicas (Levitt y Waters, 2002:18).

\section{Parentesco "sin fronteras": transnacionalismo y la familia ampliada}

En ocasiones, las relaciones intergeneracionales están embebidas de lazos familiares extendidos transnacionalmente. En las familias transnacionales las relaciones intergeneracionales se expanden a través de las fronteras nacionales con la realidad de la separación física. Esto afecta a los hijos dejados en origen (fenómeno muy analizado en la bibliografía) y a los que -a partir de los viajes de unos y otros- quedan alejados (Levitt y Waters, 2002). La presencia de familiares en diferentes contextos nacionales se vuelve común en la experiencia de los hijos, constituyendo su vínculo con el origen migratorio de sus padres.

Con transnacionalismo nos referimos a diversas actividades, especialmente económicas y culturales, realizadas por los miembros de lo que ocasionalmente se denomina una "diáspora". Esta noción "resalta las interconexiones sociales, económicas y políticas a través de las fronteras nacionales y culturales capacitando a los individuos a sostener identidades y lealtades múltiples, creando nuevos productos culturales

texto como una manera de evitar problemas (Foner, 2009).

13. Portes y Rumbaut (2001) llaman "aculturación consonante" a la "asimilación" simultánea de ambas generaciones a la sociedad de destino. Esto resulta en que los hijos se sientan menos avergonzados de sus padres y acepten con más facilidad su guía, reduciendo los conflictos intergeneracionales (Foner, 2009:8). Asimismo, el concepto de aculturación ha sido fuertemente criticado por partir de la premisa falsa de pureza y aislamiento de la cultura. 
GavAzzo, Natalia - "La diasporización de los hijos..."

que usan elementos de una variedad de configuraciones, y ejercita una membresía política y cívica múltiple" (Levitt y Waters, 2002:6). Así, las identidades construidas por estas "colectividades diaspóricas" a través del espacio a partir de sus conexiones, no están fijadas "en” o ligadas “a” una única localidad (Hannerz, 1996). Los viajes al lugar de origen, como prácticas de la transnacionalidad de las familias migrantes, constituyen elementos importantes en la estructuración de las relaciones de parentesco y vinculan a padres e hijos. Son ocasiones ricas para que los primeros den cuenta de su capital cultural de origen. Las entrevistas con hijos de bolivianos y paraguayos recuperan estas conexiones y el lugar que ocupan en sus vidas. Cuando se la consulta por los viajes de parientes de Bolivia a la Argentina, Nancy comenta que:

La mayoría de mis parientes...Es que es mitad y mitad. Vienen a trabajar a Argentina, todavía hoy, y caen en mi casa porque no tienen otro lugar. $\mathrm{O}$, si tienen otra tía cercana, también caen a ese lugar. $\mathrm{Mi}$ casa queda a 2 cuadras de la casa de otra tía que tengo; a veces caen ahí también. Bueno, la cosa es que mis parientes de Bolivia, siempre están cayendo; constantemente por mi casa, para buscar laburo; trabajar un tiempo (...) parientes, bueno, paisanos del pago de mi viejo. Por ahí, yo les digo "tío” de respeto ¿qué sé yo si son mis tíos? Como en este caso, que en realidad eran vecinos; quizás, parientes lejanos. Entonces, están en alguna línea de parentesco, seguro. (...) Por lo general, siempre han venido más hombres. Han venido primas también, mías, pero no, no les gustó mucho; vinieron para trabajar de empleadas domésticas, cama adentro; hay varias primas mías que terminaron en Buenos Aires.

Puede decirse que el transnacionalismo no recupera solo prácticas, sino también los retornos imaginarios al lugar de origen a través de la memoria, el redescubrimiento y la nostalgia cultural: un "transnacionalismo emocional" (Levitt y Waters, 2002:22). Las imágenes del lugar visitado quedan en la memoria de los hijos como una referencia al país de origen de los padres que en su propia ciudad natal, Buenos Aires, les es “adjudicada" por genealogía. El lugar de origen no es solo un lugar físico 
real, es "el lugar del deseo de uno de regresar a la imaginación propia" (Op.Cit., 2002:24. Traducción propia). El incorporarse a una comunidad cuyas "actividades culturales" (como las festividades religiosas, encuentros cívicos y eventos artísticos) son frecuentes, tiene enormes ventajas para los hijos que quieran conocer más sobre Bolivia y Paraguay ${ }^{14}$. De hecho, ellos no precisan construir lazos transnacionales o viajar de sus hogares para tener acceso a sus lugares de origen.

Así, los migrantes se vinculan a parientes ubicados en distintos países, sea por el envío de remesas, o por viajes de y a los lugares de origen. Analizando la influencia de la feminización de las migraciones en la restructuración de los roles de género y de las relaciones familiares, específicamente las inter-generacionales, Pedone (2010) propone que "los procesos de adaptación de los hijos e hijas de familias migrantes en origen y destino" suponen "nuevos desafíos en un contexto migratorio transnacional” (Op.Cit., 2010:11). Esto implica cambios en el rol de las mujeres en la familia y especialmente en relación a los hijos. Muchas migrantes dejan su rol de cuidadora en origen y postergan su autonomía personal y profesional para migrar a cuidar niños, ancianos y hogares a cambio de un salario en el así llamado "primer mundo" (Op.Cit., 2010:11). Lo que se espera de la madre es diferente al rol del padre y la separación física con el hijo es vivida de modos marcadamente opuestos: en tanto que el segundo, al emigrar y separarse del hijo, cumple con su "tarea de proveedor", la primera se siente más "culpable" y supuestamente "debe sufrir" la distancia de una manera más desgarradora.

Al respecto, Walter cuenta:

Mi papá volvió después de 20 años; se fue de Bolivia y no quería volver nunca más; después, cuando volvió, quería ir todos los años (...) Parece que tuvo una mala experiencia, algún mal recuerdo; qui-

14. Esto incluye la posibilidad de viajar a Bolivia o Paraguay para algunas celebraciones importantes. Un caso interesante es el del Carnaval de Oruro del que participan cada vez más los hijos de bolivianos que asumen que están representando a la comunidad de residentes en Argentina. 
GAVAzzo, Natalia - "La diasporización de los hijos..."

zás, la vida no fue tan buena como él quería en Bolivia; entonces, no quería volver a eso. Mi viejo fue alguien que, desde que yo lo conocí, siempre laburó para los demás; siempre, toda su vida, giró guita. De chico, de grande; yo vine acá y giraba guita para Bolivia; ahora se fue a EEUU y sigue girando guita para mi vieja. Se iba a España, a África y era guita para nosotros. Mi viejo vivió laburando, vivió afuera, vivió una vida por su familia, digamos. Y la que se encargó de criarnos más, es mi vieja; la que estuvo más con nosotros, es mi vieja. Por eso el lazo que nos une, tan grande.

Esto tiene efectos diferentes entre bolivianos y paraguayos en función de los diversos grados de feminización que presentan ambos colectivos migratorios ${ }^{15}$. Al igual que con los padres, la distancia física con los parientes puede generar extrañamiento en unos casos y, en otros, -sobre todo si se mantiene un contacto frecuente- mermar la identificación común entre distintas generaciones. Inclusive cuando las prácticas transnacionales no juegan un rol preponderante en la vida cotidiana de los hijos, eventos como los viajes a origen construyen "compromisos" con parientes fuera del ámbito del hogar materno-paterno que pueden tener un valor y atractivo para los hijos (tanto por las circunstancias en las que ocurren, como por las dificultades que emergen al crearlos).

Los vínculos con los parientes que residen en el país de origen de los padres pueden afectar los sentimientos de pertenencia que cada generación tenga al respecto de Bolivia y Paraguay. Las diferencias en la visión sobre estos lugares pueden diferir y generar nuevas tensiones entre padres e hijos.

De acuerdo a lo que se observó etnográficamente, los lazos transnacionales de los padres y de los espacios sociales trasnacionales que engendren, influyen en la vida de la "generación de los hijos". Al "querer saber más sobre las historias familiares y sus hogares ancestrales", los

15. Las "configuraciones nacionales" respecto al género, la clase y la etnicidad difieren entre ambos países de origen. Además, la influencia del estigma atribuido por la imaginación local respecto de los bolivianos difiere notablemente de los paraguayos. Véase Gavazzo (2012). 
hijos frecuentemente incorporan elementos de esas narrativas y experiencias trasnacionales en sus propios conceptos sobre sí mismos (y para auto-presentarse) $)^{16}$.

\section{Reflexiones finales: la inter-subjetividad en las identificaciones de los hijos}

En este artículo se pretendió mostrar que "a pesar de que la familia inmigrante puede convertirse en el campo de batalla entre generaciones, esta caracterización es demasiado radical y unidireccional. Las relaciones entre las generaciones están repletas de inconsistencias y contradicciones y cambian en diferentes contextos y a través del tiempo. En muchos, probablemente mayoría de los casos, el conflicto está mezclado con cooperación y cuidado, y el rechazo de algunos estándares y prácticas de los padres va acompañado de aceptación de los otros" (Foner, 2009:8). Esto pudo observarse mediante la síntesis de nuestras conclusiones sobre los testimonios de nuestros entrevistados (inmigrantes o sus descendientes nacidos en Argentina), quienes combinan diversas estrategias para "refugiarse" de posibles hostilidades y progresar económica y socialmente.

Este entramado de factores muestra las heterogéneas formas de identificación de los hijos de bolivianos y paraguayos respecto de sus pertenencias, las culturas de sus padres y las identificaciones (y diferenciaciones) con ellos. Así, no cabe una "simplificación" de la generación genealógica que es objeto de este artículo (a saber, "los hijos”), obligándonos a enfocar la mirada sobre los sujetos para poder recuperar parte de esa heterogeneidad. ¿Qué define a los hijos como tales y los diferencia de sus padres más allá de la nacionalidad? Una de las posibles respuestas la encontramos en la intersubjetividad implicada en las relaciones intergeneracionales entre inmigrantes y sus hijos, tal como se desprende de

16. Toda subjetividad implica intersubjetividad y el "ser" (self) debe ser entendido como un producto siempre emergente de la historia de su constitución (MerlauPonty, 1964:14). 
GAVAzzo, Natalia - "La diasporización de los hijos..."

los relatos de los descendientes respecto de sus formas de identificarse (o no) con la "cultura de origen".

La idea de "transmisión de una cultura de origen" de padres a hijos es errónea en tanto supone acríticamente una continuidad (casi generacional/genética) de aspectos sociales y culturales. Sin embargo, la construcción activa de una memoria común constituye un elemento fundamental de las relaciones entre padres e hijos en las familias migrantes, provocando un sentido diaspórico (en los términos discutidos en la introducción) para aquellas prácticas transnacionales de las familias. Aunque "desde afuera" se suele naturalizar ese vínculo (y adherirle entonces un conjunto de atributos y pertenencias), apoyados por el carácter biológico asignado tanto a la paternidad/maternidad como a la filiación, la diversidad de formas de identificación registradas demuestra que lo que entendemos por cultura se construye en cada apelación que se haga a ella, de acuerdo a quién la defina, cuándo y con qué fines (Wright, 1998). Las fronteras entre culturas pueden o no coincidir con las fronteras de las identificaciones, las que son en todos los casos contextuales y situadas. Lo que entendamos por ella responde a ciertas sedimentaciones y erosiones que permiten hablar de configuraciones con lógicas específicas que remiten a continuidades, pero también a cambios cristalizados con el tiempo (Grimson, 2011). Estas lógicas permiten analizar a la generación de los hijos como un grupo social particular, con influencias similares (que son los significantes compartidos por padres e hijos), pero reapropiadas de modos específicos en cada sujeto. Las continuidades identitarias, cuando ocurren, si bien implican los mismos significantes, pueden resultar en significados diferentes para cada generación.

Las identificaciones y las prácticas culturales de los hijos -como descendientes de inmigrantes bolivianos y paraguayos- son variadas y cambiantes, incluso llegando a expandirse a través de las fronteras nacionales, "diasporizándose” y modificándose a través del tiempo (incluso reinventando el significado de algunas categorías para responder al estigma). En un contexto "europeizante" como el de la Argentina actual (y más aún en la ciudad capital), los hijos frecuentemente se ven 
interpelados como "otros", y esta situación constituye una imposición que los "marca", restringe sus opciones de identificación, sus prácticas culturales, su identidad y la cultura de sus padres y parientes bolivianos y paraguayos. No existe "herencia" entonces, sino reinvención y reconstrucción permanente de una memoria familiar en los hijos, que deben elegir a diario cómo resolver los dilemas culturales e identitarios que les son impuestos por ser considerados "migrantes" sin realmente serlo.

\section{Bibliografía}

BEHERÁN, M. (2007). "El tratamiento de la diversidad cultural en las escuelas públicas primarias de la ciudad de Buenos Aires". Tesis correspondiente a la Maestría en Políticas de Migraciones Internacionales, Universidad de Buenos Aires, Buenos Aires.

BENENCIA, R. (2006). "Bolivianización de la horticultura en la Argentina. Procesos de migración transnacional y construcción de territorios productivos", en Grimson, A; Jelin, E. Migraciones regionales hacia la Argentina. Diferencia, desigualdad y derechos, Prometeo Libros, Buenos Aires, pp.135-167

BRUBAKER, R. y F. COOPER. (2002). "Más allá de identidad”, en Apuntes de investigación $\mathrm{n}^{\mathrm{0}} 7$, Buenos Aires.

CAGGIANO, S. (2005). Lo que no entra en el crisol. Inmigración boliviana, comunicación intercultural y procesos identitarios, Prometeo Libros, Buenos Aires.

CERRUTI, M. (2009). "Diagnóstico de las poblaciones de inmigrantes en la Argentina", Serie de documentos de la Dirección Nacional de Población 02, Secretaría del Interior, Ministerio del Interior. Organización Internacional para las migraciones (OIM).

CLIFFORD, J. (2002). Itinerarios transculturales, Gedisa, Barcelona.

FEIXA, C. (1996). Antropología de las edades. Disponible en: Biblioteca virtual de Ciencias Sociales. http://www.cholonautas.edu.pe/modulo/ upload/C\%20Feixa.pdf

FONER, N. (2009). "Introduction: Intergenerational Relations in Immigrant 
Gavazzo, Natalia - "La diasporización de los hijos..."

Families", en Across Generation: Immigrant Families in America, New York University Press, New York

GAVAZZO, N. (2012). "Hijos de bolivianos y paraguayos en el área metropolitana de Buenos Aires. Identificaciones y participación, entre la discriminación y el reconocimiento". Tesis doctoral. Facultad de Filosofía y Letras. Universidad de Buenos Aires.

(2013). "No soy de aquí, ni soy de allá... Alterización y categorías de identificación en la generación de los hijos de inmigrantes bolivianos y paraguayos en Buenos Aires", en Revista Claroscuro, (12): 73-95.

GHIARDO, F. (2004) “Generaciones y Juventud: una relectura desde Mannheim y Ortega y Gasset”, en Revista Última Década No 20.: CIDPA. Viña del Mar, Chile.

GRIMSON, A y M. GODOY-ANATIVIA (2003). "Introducción”, en Revista Estudios Migratorios Latinoamericanos, Año 17, nº52, Buenos Aires, pp-507-517.

GRIMSON, A. (2011) Los Límites de la Cultura. Siglo XXI. Buenos Aires.

HALPERN, G. (2009). Etnicidad, inmigración y política. Representaciones y cultura política de exiliados paraguayos en Argentina, Editorial Prometeo, Buenos Aires.

HANNERZ, U. (1996). Conexiones transnacionales, Cátedra, Madrid.

KROPFF, L. (2008). "Apuntes conceptuales para una antropología de la edad", en Avá, revista de antropología, Programa de Postgrado en Antropología Social de la Universidad Nacional de Misiones. Misiones, Argentina.

LEVITT, P y M. WATERS (2002). The Changing Face of Home. The Transnational, Russell Sage Foundation, Nueva York.

MARGULIS, M. y M. URRESTI (1999). La Segregación Negada. Cultura y Discriminación Social, Editorial Biblos, Buenos Aires.

MERA, C. (2010). "El concepto de diáspora en los estudios migratorios: reflexiones sobre el caso de las comunidades y movilidades coreanas en el mundo actual", en Revista Historia, 12: 43-56.

MERENSON, S. (2015). "Del exilio a la diáspora. Lenguajes y mediaciones 
en el proceso de diasporización uruguayo", en Horizontes Antropológicos, 21 (43): 211-238.

MERLAU-PONTY, M. (1964) Lo visible y lo invisible, Gallimard, Paris.

NOVARO y ots, (2008) "Sonidos del silencio, voces silenciadas. Niños indígenas y migrantes en escuelas de Buenos Aires", en Revista Mexicana de Investigación Educativa, Vol. 13, Núm. 36, México.

OTEIZA, E; S. NOVICK y ARUJ R.. (1997). Inmigración y Discriminación. Políticas y discursos, Grupo Editor Universitario, Buenos Aires.

PEDONE, C. (2010). "Lo de migrar me lo tomaría con calma: representaciones sociales de jóvenes en torno al proyecto migratorio familiar", en Tránsitos migratorios: contextos transnacionales y proyectos familiares en las migraciones actuales, Ediciones de la Universidad de Murcia, España.

PORTES, A ed. (1997) The Economic Sociology of Immigration. Essays on Networks, Ethnicity and Entrepreneurshi, Russell Sage Foundation, New York.

PORTES, A. y R. RUMBAUT (2001). Legacies: the Story of the Immigrant. Second Generation, Russell Sage Foundation, Nueva York.

PORTES, A y M. ZHOU (1992). "En route vers les sommets: nouvelles perspectivas sur la question des minorités ethniques.", en Revue Européenne des Migrations Internationales, vol 8, nº 1, pp.171-192.

RATIER, H. (1972). Villeros y villas miseria, Ed. CELA, Buenos Aires.

SINNISI, L (1999). "La relación "nosotros - otros" en espacios escolares multiculturales. Estigma, estereotipo y racialización”, en M. R. Neufeld y J. A. Thisted (compiladores) De eso no se habla...." Los usos de la diversidad en la escuela, Eudeba, Buenos Aires.

WRIGHT, S. (1998) "La politización de la "cultura'”, en Anthropology Today, Vol 14. N¹. (7-15).

Recibido: 09/09/2017

Evaluado: 24/11/2017

Versión final: 15/02/2018 